\title{
LUGARES DE MEMORIA Y AGENCIAMIENTOS GENERACIONALES: LUGAR, ESPACIO Y EXPERIENCIA
}

\author{
MAURICIO SEPÚlVEDA GALEAS* \\ ANDREA SEPÚlVEDA GATICA ** \\ ISABEL PIPER SHAFIR *** \\ LELYA TRONCOSO PÉREZ ${ }^{* * * *}$
}

\begin{abstract}
RESUMEN
En este artículo analizamos la interacción de jóvenes nacidos en postdictadura con dos lugares de memoria; Londres 38 y Villa Grimaldi, ambos ex centros de tortura de la dictadura chilena (1973-1990). A partir del análisis del registro audiovisual de esta interacción, señalamos que la experiencia posibilita el despliegue y articulación de conocimientos, emociones, percepciones, imaginación y memorias, tensionando las disputas por la significación del pasado reciente entre las generaciones según su acercamiento a este pasado. Reflexionamos finalmente acerca de la relevancia de posicionar a los jóvenes como constructores de las memorias del pasado reciente.
\end{abstract}

\section{PALABRAS CLAVE: MEMORIAS GENERACIONALES, LUGAR DE MEMORIA, JÓVENES}

* Chileno. Doctor en Antropología por la Universidad Rovira i Virgili, Tarragona, España. Profesor asistente del Departamento de Psicología de la Universidad de Chile e investigador postdoctoral CONICYT. Miembro del Programa Psicología Social de la Memoria, Universidad de Chile.

E-Mail: sepulveda.galeas@gmail.com.

** Chilena. Licenciada en Psicología por la Universidad de Chile, y diplomada en Psicología Social Crítica y Procesos Políticos. Miembro del Programa Psicología Social de la Memoria, de la Universidad de Chile. E-Mail: an@ug.uchile.cl.

*** Chilena. Doctora en Psicología Social por la Universidad Autónoma de Barcelona. Académica del departamento de Psicologia de la Universidad de Chile. Coordinadora del Porgrama Psicología Social de la Memoria de la misma Universidad. E-Mail: ipiper@u.uchile.cl.

**** Chilena. Licenciada en Psicología, Universidad de Valparaíso. Máster en Psicología Social por la Universidad Autónoma de Barcelona y Master of Science in Gender Studies por la Universidad de Lund, Suecia. Miembro del Programa Psicología Social de la Memoria, Universidad de Chile.

E-Mail: lelya.troncoso@gmail.com.

Artículo desarrollado en el marco del proyecto: «Memorias, generaciones, experiencia, género y materialidades: análisis semiótico material de discursos de novíctimas de violaciones a los derechos Humanos», financiado por Fondo de Innovación en Investigación IBJGM, Universidad de Chile. 


\title{
LUGARES DE MEMÓRIA E AGENCIAMENTOS GERACIONAIS: LUGAR, ESPAÇO E EXPERIÊNCIA
}

\begin{abstract}
RESUMO
Neste artículo analisamos a interação de jovens nascidos na pós-ditadura com dois lugares de memória; Londres 38 e Villa Grimaldi, os dois ex-centros de tortura da ditadura chilena (1973-1990). A partir da análise do registro audiovisual desta interação, mencionamos que a experiência possibilita a dispersão e articulação de conhecimentos, emoções, percepções, imaginação e memórias, puxando as disputas pela significação do passado recente entre as gerações segundo sua aproximação com este passado. Refletiremos finalmente sobre a relevância de posicionar os jovens como construtores das memórias do passado recente.
\end{abstract}

PALAVRAS CHAVE: MEMÓRIAS GERACIONAIS, LUGAR DE MEMÓRIA, JOVENS

\section{MEMORY SITES AND GENERATIONAL AGENCIES: SITE, SPACE AND EXPERIENCE}

\begin{abstract}
In this article we analyze the interaction of young people born in postdictatorship from two memory sites, Londres 38 and Villa Grimaldi, both former torture centers during the Chilean dictatorship (1973-1990). Audiovisual recordings of these interactions were analyzed and from this analysis we suggest that the experience enables the expansion and coordination of knowledge, emotions, perceptions, imagination and memories, bringing disputes over the significance of the recent past between generations into tension, depending on their approach to this past. Finally, we reflect on the importance of positioning young people as constructors of memories of the recent past.
\end{abstract}

KEY WORDS: GENERATIONAL MEMORIES, MEMORY SITE, YOUTH 


\section{INTRODUCCIÓN}

Ya que ustedes ignoran un asunto que se los voy a conversar: estuve en la casa del señor Allende, hace unos cuantos años, en una de las propiedades de é1, cerca del Restaurante El Flete, adonde tuvo el Padre Mío la industria industrial, ahí, antes ahí, con el que tiene compromisos, pero cuando estuve en la casa, el Padre Mío no me presento a1 señor Allende, a don Luciano Diez, a la señorita Rosina que era la reina Isabel, a la princesa Alejandra, que vive ahí mismo y la señorita Nené que le dicen. A la señorita Lala me la presentó en esos años en un día de Año Nuevo, a don Ramón Diez que es Salvador Allende.

Diamela Eltit, El padre mío

LAS DISCUSIONES Y REFLEXIONES en torno a las memorias del pasado reciente de nuestro país, referidas a la dictadura militar (1973-1990), mayoritariamente han sido lideradas por agrupaciones de familiares de las víctimas de la represión, organismos de derechos humanos y sociedad civil, cuyos miembros - por lo general - fueron partícipes y/o testigos directos de los hechos del pasado reciente. Estas organizaciones han promovido acciones que potencian tanto la preservación como la promoción de las memorias vinculadas a las acciones represivas ocurridas durante la dictadura militar. Estas últimas, a cuarenta y un años de los sucesos, siguen siendo puestas en discusión y tensión en distintos ámbitos sociales, políticos y culturales.

En el escenario actual, las nuevas generaciones de jóvenes nacidos con posterioridad al golpe militar y período dictatorial, constituyen un grupo fundamental al que se orientan los discursos y acciones de memoria sobre el pasado reciente. En este sentido, los y las jóvenes de postdictadura, devienen en un tipo de sujeto relevante para las políticas de memoria, en tanto destinatarios de múltiples acciones que remiten y lidian con el pasado y que disponen, en su puesta en juego, bien una reproducción del orden social existente, bien un cuestionamiento, disensión y/o modificación de éste (Reyes, Muñoz y Vázquez, 2013).

Este nuevo actor social, compuesto por aquellos nacidos posteriormente a la dictadura militar; es decir, quienes «no lo vivieron» de modo directo, en primera persona, son hoy fundamentales en la construcción de memorias (Vázquez, 2001). Más aún cuando son pensados como sujetos con competencias para referirse en actitud objetivante a las entidades del mundo, es decir como sujetos de discurso con capa- 
cidad para apropiarse de los objetos, tanto sociales y simbólicos, como materiales; es decir, cuando son entendidos como agentes sociales (Reguillo, 2000).

Es por ello, que consideramos necesario pensar la relación entre los procesos de memoria colectiva, socialización y transmisión intergeneracional, entendiendo cómo estos ámbitos se relacionan entre sí, y por tanto, necesarios de ser pensados articuladamente.

En este marco, en el presente artículo nos proponemos analizar dicha relación desde la interacción que jóvenes nacidos en postdictadura (entre 15 y 30 años) articulan con los lugares de memoria, particularmente con Londres $38^{1}$ y Villa Grimaldi. ${ }^{2}$ Esto a partir del análisis del material discursivo y audiovisual producido en el marco del Proyecto Fondecyt (2011) titulado «Construcción de relatos generacionales sobre nuestro pasado reciente (1970-1990) en el escenario de cuatro lugares de memoria de Santiago».

Adscritas a un proyecto de psicología social crítica comprometido con un dialogo interdisciplinar, utilizaremos como categorías analíticas las nociones de juventud y generación propuestas por Piere Bourdieu (1990) y Karl Manheim (1993) respectivamente. De forma complementaria, utilizaremos la distinción planteada por Michel de Certau (2000) respecto a lugar y espacio y la noción crítica de experiencia de Joan Scott (1991).

1 Londres 38 es una casona ubicada en pleno centro de Santiago de Chile, en 1973 se convirtió en el centro de operaciones de la Dirección de Inteligencia Nacional (DINA), llevándose a cabo en dicho lugar tanto planificaciones como procesos concretos de detención, tortura, exterminio y procesos de desaparición forzada de opositores a la Dictadura. Hasta donde se ha podido establecer la DINA hizo desaparecer o ejecutó a 96 personas en este lugar. En el año 2005 organizaciones de ex detenidos sobrevivientes, familiares de detenidos desparecidos y ejecutados y ex militantes de izquierda recuperaron el espacio para visibilizar su historia.

2 La corporación Parque por la Paz Villa Grimaldi fue inaugurada en 1997 y es un lugar de memoria ubicado en Peñalolén, Santiago de Chile el cual funcionó a partir de 1974 como el denominado Cuartel Terrenova, centro secreto de secuestro, tortutra y desaparaición de la DINA. El Parque opera como lugar de recuerdo, recogimiento y reflexión sobre el terrorismo de Estado, entregando a su vez recursos pedagógicos para quienes se interesan en aprender sobre derechos humanos. 


\section{MEMORIA COLECTIVA Y CAMPO SOCIAL}

El concepto de memoria colectiva, acuñado por Halbwachs en 1964, remarca su carácter social y procesual en tanto que producto de significados compartidos y construidos a través de las relaciones sociales, y actualizados a través del lenguaje y las prácticas sociales (Vázquez 2001, Calveiro 2006, Tocornal y Vergara, 1998; Piper et al., 2013). En este sentido, el pasado se construye y reconstruye a partir del presente, de sus intereses y proyecciones futuras, a través de prácticas discursivas que le otorgan valor y significado (Piper 2002). Es por esto, que se puede decir que el pasado nunca es el mismo (Halbwachs, 2004).

Desde esta perspectiva, la memoria no es una reproducción del pasado, por lo cual tiene el potencial de transformar la realidad, posibilitando nuevas pautas a través de las cuales puede ser interpretada (Vázquez, 2001). Cuando hacemos memoria «sostenemos, reproducimos, extendemos, engendramos, alteramos y transformamos nuestras relaciones» (Vázquez, 2001:115). Es por esta característica, que se trata de un proceso dinámico y conflictual, que cambia en la relación y también nuestras relaciones (Jedlowski y Rampazi, 1991 citado en Vázquez, 2001). En este sentido la memoria colectiva funge como marco interpretativo en diputa constituyéndose en la condición de posibilidad de reconocimiento, aprensión e inteligibilidad del acontecer.

Además, el dar énfasis en que la memoria es un proceso realizado desde el presente permite comprender que esta construcción está atravesada también por los conocimientos que hemos ido adquiriendo a lo largo de nuestra vida, tengan estos que ver, o no, con el pasado o con la memoria. Conocimientos que provienen de la socialización, de nuestras relaciones, de las lecturas, de la escolarización, de los mass media, etcétera. Por ello, incluso una persona que no ha participado en un acontecimiento, puede contribuir a la construcción de esa memoria (Blondel, 1928; Connerton, 1989; Billing y Edwards, 1994; Middleton y Edwards, 1990; citado en Vázquez, 2001). En efecto, los sujetos pueden elaborar sus memorias narrativas porque hubo otros que lo han hecho antes, y han logrado transmitirlas y dialogar sobre ellas (Jelin, 2001). Es entonces como las nuevas generaciones, no sólo son herederas y transmisoras del pasado, sino que también juegan un rol activo en la construcción de su pasado, disputando sus significaciones posibles.

En este sentido, la memoria colectiva puede ser pensada como un campo social, noción propuesta por Pierre Bourdieu (2001) mediante 
la cual alude a un espacio social específico en el que las relaciones o sistemas de posiciones sociales se definen de acuerdo a un tipo especial de poder o capital detentado por los agentes que entran en lucha o en competencia; es decir, que juegan en ese espacio social. Esto quiere decir que las posiciones de los agentes se definen históricamente de acuerdo a su situación actual y potencial en la estructura de distribución de las diferentes especies de poder, de capitales, cuya posesión condiciona el acceso a los provechos específicos que están en juego en el campo (Bourdieu y Wacquand, 2005).

Con esta metáfora espacial, Bourdieu reivindica el primado de las relaciones por sobre cualquier tipo de substancialismo, donde los individuos existen como agentes y no como individuos biológicos, actores o sujetos, pues se constituyen como tales y actúan en el campo siempre que posean las propiedades necesarias para ser efectivos, para producir efectos en ese campo. En tal sentido, como campo social, la memoria colectiva puede ser entendida como un sistema de diferencias - de asimetrías - en el que el valor de cada posición social no se define en sí misma, sino que se mide por la distancia social que la separa de otras posiciones, inferiores o superiores. Ahora bien, aunque esas distancias sociales varían en función de los cambios en esa estructura de distribución de diferencias de capital, también existen formas de codificación e institucionalización de las distancias sociales las cuales van a ser reforzadas mediante la ley, las costumbres, las creencias, etcétera (García, 2001).

Si la estructura del campo es un estado de la relación de fuerza entre los agentes o las instituciones que intervienen en la lucha, de otro modo, de la distribución desigual del capital específico que ha sido acumulado durante luchas anteriores y que orienta las estrategias ulteriores (Bourdieu, 1990), cabe interrogarse por la posición diferencial que adquieren en este campo social las practicas de memoria ejercida por los y las jóvenes nacidos en postdictadura.

En relación a dicha interrogante, será el propio Bourdieu quien va a proporcionar claves de lecturas que resultarán relevantes para entender tanto las posiciones que adquieren los y las jóvenes en el campo de la memoria, como también sus luchas por reconfigurarlas. En efecto, en su ya clásico texto «La juventud no es más que una palabra», Bourdieu señala que «La representación ideológica de la división entre jóvenes y viejos otorga a los más jóvenes ciertas cosas que hacen que dejen a cambio otras muchas a los más viejos» (Bourdieu, 1990:119). Y más adelante agrega «Esta estructura, que existe en otros casos (como en 
las relaciones entre los sexos), recuerda que en la división lógica entre jóvenes y viejos está la cuestión del poder, de la división (en el sentido de repartición) de los poderes. La clasificación por edad (y también por sexo, o, claro, por clases...) viene a ser siempre una forma de imponer límites, de producir un orden en el cual cada quien debe mantenerse, donde cada quien debe ocupar su lugar» (Bourdieu, 1990:119). En este sentido, las relaciones asimétricas experimentadas en el campo de la memoria se encuentran atravesadas por las divisiones de clases de edad, otorgándoles una posición de subalternidad a los y las jóvenes con respecto al mundo adulto. Subordinación a un determinado relato, o versión sobre los hechos del pasado, que tal como veremos más adelante, se verá reforzada mediante la apelación a la experiencia, al «yo estuve ahí», que en tanto capital simbólico, legitima el discurso adulto sobre el pasado reciente en desmedro de los discursos emergentes de las generaciones de postdictadura.

Ahora bien, tal como señala Bourdieu, aquellos que dentro de un estado determinado de la relación de fuerzas, monopolizan el capital específico — en este caso la «verdad histórica» o «memoria verdadera»- como fundamento del poder de su autoridad, se inclinan hacia estrategias de conservación mediante el relato ortodoxo, mientras que aquello que disponen de menos capital (que en este caso suelen ser los más jóvenes) se inclinarán hacia un relato heterodoxo que funge como estrategia de subversión del orden custodiado por los primeros (Bourdieu, 1990).

En la misma dirección, aunque desde un costado distinto, el esquema conceptual propuesto por Michel de Certeau (2000) respecto a las prácticas de espacio resulta fecundo en tanto complementa el análisis de la memoria como espacio social derivado de los planteamientos de Bourdieu. En efecto, desde la perspectiva de este autor, se entenderá el espacio como un efecto producido por las operaciones que lo orientan, lo circunstancian, lo temporalizan y lo llevan a funcionar como una unidad polivalente de programas conflictuales. Esto quiere decir que, a diferencia de un sitio propio que vendría a ser el lugar, el espacio carecería de univocidad y de estabilidad. De Certeau sintetiza su concepto de espacio de la siguiente forma: el espacio es un lugar practicado. En consecuencia, de acuerdo a éste, un lugar, a diferencia del espacio, sería el orden (cualquiera que sea) según el cual los elementos se distribuyen en relaciones de coexistencia. En el orden imperaría la ley de lo «propio», pues los elementos considerados estarían unos al lado de otros, cada uno situado en un sitio propio y distinto 
que cada uno define. Un lugar es pues una configuración instantánea de posiciones que implica e indica estabilidad. Como señala el mismo De Certeau «el espacio es al lugar lo que se vuelve la palabra al ser articulada». En tal sentido, como veremos más adelante, se puede señalar que las y los jóvenes en su interacción con los lugares memoria, en sus diversas formas de apropiación, hacen de estos lugares de memoria unos espacios socialmente practicados.

\section{MEMORIAS GENERACIONALES Y AGENCIA}

Tal como ha sido observado en investigaciones anteriores (Piper et al., 2011; Piper et al., 2013) las distintas posiciones de los agentes en el campo de la memoria se produce de forma diferenciada conforme a lo que Karl Mannheim (1993) conceptualiza como posición, conexión y unidad generacional. Lo primero, si bien remite a una comunidad de fechas de nacimiento al mismo tiempo la excede pues necesariamente remite a una misma comunidad de vida histórica; lo segundo remite a la existencia de procesos sociohistóricos compartidos; y lo tercero al establecimiento de vínculos concretos mediante la participación real en un destino común, así como proyecciones y sentidos específicos que se debaten al interior de una problemática de renovación histórica. En este sentido, posición, conexión y unidad generacional relevan el carácter agencial que adquieren las memorias generacionales en tanto por un lado refieren a una comunidad imaginada que se convoca al ser nombrada (Baumman, 2007) como tal, y por otro lado, en tanto refieren a las luchas simbólicas asociados a la producción de sujetos sociales en el marco de sus disputas políticas (Bourdieu, 2000).

En este sentido, el concepto de generación sociohistórica acuñado por Mannheim (1993) considera la conexión generacional como un elemento capaz de dar cuenta de la potencialidad de cambio y diversidad dentro del recuerdo colectivo, rompiendo la presunción de estabilidad (ortodoxia/hegemonía) que se le podría atribuir a la memoria. (Guichard y Enriquez, 2011). Así entonces, las nociones de memoria colectiva de Halbwachs $(1925,1950)$ y de generación sociohistórica de Mannheim son complementarias. La primera enfatiza los elementos estables del recuerdo - como serían por ejemplo sus marcos sociales-, mientras la segunda se refiere a sus elementos dinámicos y de cambio.

Por otro lado, de acuerdo a Bauman (2007), las generaciones harían referencia a una comunidad imaginada, una comunidad que es convocada performativamente al ser nombrada. Es decir, de acuerdo a 
éste último autor, las generaciones no existirían como entidades objetivas, sino que serían construidas performativamente para fines diversos. Así el descubrimiento de la «generación» tal como ha sido canonizado por Mannheim, en el sentido de un tipo de sujeto colectivo que actúa de acuerdo a ciertos intereses particulares, es para Bauman en sí mismo un logro de la generación de la gran guerra. Es decir, se constituye performativamente aquello que pretende nombrar o descubrir.

Ambas conceptualizaciones permiten problematizar la cuestión del agenciamiento generacional en el campo de las políticas de la memoria, entendiendo esta última como una «acción deliberada establecida por los gobiernos o por otros actores políticos o sociales con el objeto de conservar, transmitir y valorizar el recuerdo de determinados aspectos del pasado considerados particularmente significativos o importantes» (Groppo, 2002:192). En este sentido, el agenciamiento generacional actuaría simultáneamente como vector de conservación (orden hegemónico) y/o cambio (contramemoria), y como vector identitario. Y es que la laboriosidad de esta memoria insatisfecha, no se da nunca por vencida, perturbando la voluntad de sepultación oficial del recuerdo, mirado simplemente como depósito fijo de significaciones inactivas (Richard, 2010).

\section{ALCANCES METODOLÓGICOS}

Se registraron de modo audiovisual las visitas de jóvenes ente quince y treinta años, por medio de dispositivos audiovisuales llamados «Acompañamiento dialógico interactivo». Estos corresponden a una innovación metodológica, la cual consiste en un recorrido libre del sitio por parte de los participantes, siempre acompañados por un investigador o investigadora quien registra en video su interacción con el espacio, y con quien dialoga comentando aquellos aspectos que consideraran relevantes, tales como sensaciones o ideas y otros elementos significativos para el visitante. Luego, para trabajar el material, se realizaron transcripciones empleando el sistema de transcripción de Gail Jefferson (1985) el cual refiere a un conjunto de símbolos que permiten destacar ciertas características del habla que han sido consideradas como relevantes en la interacción. ${ }^{3}$

3 Las citas textuales de los relatos de los sujetos participantes en el estudio se reproducen en texto siguiendo el sistema de transcripción de Gail Jefferson (1985). 
Posterior a la instancia de acompañamiento, los jóvenes fueron invitados a participar en un grupo triangular (Conde, 2008) realizada en el mismo lugar de memoria visitado. La discusión grupal buscó indagar en sus experiencias de interacción con el lugar para profundizar en ella y en los significados que se construyen en torno a los lugares. Esta etapa, a diferencia de la anterior, contó con una pauta general de discusión mediante la cual se buscó profundizar en los relatos y experiencias de los visitantes en el marco de una conversación grupal.

Para el presente artículo, se utilizaron doce dispositivos audiovisuales correspondientes a doce recorridos realizados por jóvenes cuyas edades fluctuaban entre quince y dieciocho años, y tres de jóvenes entre dieciocho y treinta años.

Los participantes no vivieron durante el gobierno de la Unidad Popular y la dictadura militar (1970-1990), siendo personas nacidas, ya sea a fines de la dictadura militar o con posterioridad a la recuperación de la democracia. En la misma dirección, lo participantes tendrían la condición de no haber sido víctimas de violaciones a los derechos humanos, ni ser familiares directos de éstas. En tal sentido, el énfasis estuvo puesto en explorar las construcciones de memorias en las generaciones que no tuvieron la experiencia directa con la dictadura militar ni estuviesen involucrados anteriormente de manera directa en estos procesos, excluyendo para ello, además, a participantes de partidos políticos y/o alguna agrupación de defensa de los Derechos Humanos.

Estos criterios buscaron ampliar el rango de los estudios sobre lugares de memoria a los posibles usos y significados de quienes no pertenecen al universo de las víctimas de las violaciones a los Derechos Humanos.

\section{EXPERIENCIA E INTERACCIÓN EN UN LUGAR DE MEMORIA}

El análisis de los datos obtenidos permite señalar que la experiencia de recorrido de los lugares de memoria involucra al visitante en su totalidad. Esto significa que para comprender la experiencia de los jóvenes visitantes se deberá aprehender ésta como una totalidad, integrando sus conocimientos, emociones, percepciones, imaginación y memorias.

En ese horizonte cumple un rol fundamental el espacio concreto del lugar de memoria, la casa en el caso de Londres 38 y las reconstrucciones de espacios como la torre y las celdas en Villa Grimaldi, 
operan como testigos de los sucesos ocurridos, permitiendo imaginar y vivir lo que fueron los ex centros de detención. Ciertamente, los lugares como testigos constituyen una característica central de los lugares de memoria que mayor relevancia adquiere durante la visita, operando como pivote principal de los relatos (y en la mayoría de las ocasiones, exclusivo) que acompaña su recorrido. La testificación derivada de ciertas huellas o marcas en dichos lugares de memoria, lleva incluso a que se omita cualquier señalamiento que haga visible los casi cuarenta años que han transcurrido tras los hechos.

El estar ahí en el presente permite así un acercamiento material y concreto a la verdad sobre el pasado. Destacan a su vez el monumento de rieles de Villa Grimaldi, en el cual se exhiben y conservan restos de rieles de ferrocarril a los cuales victimas fueron amarradas y arrojadas al mar estando aun con vida. Adheridos a estos rieles se encontraron objetos como un botón que sirvió de prueba en investigaciones sobre estos hechos. Ver los rieles y ver el botón operan como instancias de comprobación de los hechos acontecidos.

Por ello, recorrer estos espacios, especialmente para quienes no lo vivieron, les permitirá acercarse a los sucesos relacionados al pasado reciente de manera particular, posibilitando además de la comprensión histórica sobre el pasado, sentir y vivir la experiencia de manera cercana, dando paso a una mayor legitimidad para aproximarse a esa «verdad».

Claro yo siento que es como eso, o sea pasa por una cosa que transgredes [...] no a ver cómo explicarlo. A mí me pasa que con el cuento de la tortura yo igual [...] soy súper empático o sea como que de repente entiendo mucho a las personas cuando alegan por sus familiares y todo. Pero cuando lo ves más allá dices cómo pasa por la cabeza de estos tipos el hacer tanto daño por ejemplo la misma parrilla eléctrica o las camas eléctricas y me acordé justo porque yo también he ido al Museo de la Memoria y me acordé de una, bueno de uno de los testimonios y de una actriz [...] que la a ella la torturaron de esa forma. Y no se les metían hasta ratones por la vagina. Entonces cuál es el nivel de distorsión [...] cachai de estos tipos como pa llegar a hacer eso y hacer tanto daño cuando realmente eran personas que [...] tú te ponís a pensar, ¿lo merecían realmente? cachai, ¿qué tan malo hicieron? Para qué le hicieran esa maldad (Villa Grimaldi, hombre, grupo 18 a 30 años).

El mismo caso del botón, el mismo caso del botón. Yo tampoco, no creía mucho me contaban mis tíos [...] o personas que te cuentan de repente claro el botón decían tiraban personas adentro y tú decías cómo iban a 
tirar personas ahí dentro, amarrados a algo. Entonces ahora llegar, ver un botón [...] eso como que claro, esto es verdad. De repente también se dice que muchas personas que se tiraron al mar que no tenían de dónde nombre, nada claro eran de otros países. Entonces se pasaban cuerpos, cuerpos cuerpos pa todos lados. Entonces ahora ver el botón, ver esto y claro esto es verdad. Es algo que sucedió (Villa Grimaldi, hombre, grupo 18 a 30 años).

Sin embargo, el espacio físico como testigo, no sólo se considera importante en cuanto a su rol de contenedor de una historia, sino que también lo es por su capacidad de afectación para quienes lo visitan, generando sensaciones y emociones intensas, las cuales permiten al visitante articular de un modo personal ese pasado horroroso. $\mathrm{O}$ dicho de otro modo, la experiencia en estos espacios - su práctica- permitiría al visitante aprehender desde el costado de la emoción esa suerte de memoria «encerrada, contenida en el lugar».

Es decir, además de conocimiento histórico, la casa entrega un conocimiento afectivo, permite a los visitantes sentir con el cuerpo, ser afectados por el espacio lo cual implica pensarlo, evaluarlo y sentirlo en función de dicha afectación. Las emociones en este sentido involucran una intencionalidad, una orientación hacia el objeto que nos afecta y es a su vez formado por las emociones que nos genera, construyendo de este modo un determinado posicionamiento acerca del mundo (Ahmed, 2004).

Esta conexión afectiva pasa por el acto de imaginar, lo que si bien forma parte de todas las experiencias de quienes visitan los lugares de memoria, en las generaciones más jóvenes adquiere una significación particular. Éstos, al no haber vivido aquello que se recuerda parecieran no tener otra opción que imaginar los horrores, imaginar cómo éstos ocurrieron. El trabajo de imaginar en los jóvenes adquiere la forma del bricolaje en tanto los objetos y símbolos, a veces inconexos (manchas en las paredes, perforaciones, murales, etc.) son reordenados y recontextualizados para comunicar nuevos significados (Feixa, 1999). En definitiva, el imaginar deviene en un trabajo no menos ficcional en cual concurren retazos de documentos gráficos, escritos, series de televisión, películas, historias, etcétera.

No, a mi el árbol al revés no me produjo nada , a mi lo que o sea también (...) la piscina hoy pa mi la piscina fue horrible. Yo vi la piscina y dije esto es una película de terror, porque típico que salen esos azulejos blancos todos manchados, oscuros y me imaginaba casi que en el Juego 
del Miedo cómo torturaban a las personas. Era muy terrible. La piscina la encontré muy cargada, muy heavy si no íbamos a pasar por la piscina, pero yo la vi y dije no pero esto está denso, muy denso. Y de ahí la torre oh (Villa Grimaldi, mujer, grupo 18 a 30 años).

Eso fue lo más por lejos lo más terrible. La tor-más que nada la torre, las fotos [...] a mí el estar adentro de la torre y ver pa arriba. Yo ni siquiera subí porque el miedo arriba era ya mucho. Y después salí, me gustó como que trascienda: que lo más importante sea lo pacífico, eso me gusta. Como que no me gustan estas imágenes así porque me dan miedo, no me dan ganas de venir al lugar de nuevo. Pero por ejemplo donde salen esos nombres que lo encontré precioso (Villa Grimaldi, mujer, grupo 18 a 30 años).

Los jóvenes se conectan con las experiencias represivas vividas por las/los prisioneros, empatizando con sus sentimientos, lo que genera en el visitante afectos ligados al miedo, la angustia, la indefensión. En este sentido, la imaginación desplegada en el «lugar de los hechos» genera en el visitante la sensación de construir una memoria 'más certera y real' a lo que realmente sucedió. Es así como visitar la casa permite acercarse al pasado desde un modo distinto al que lo haría leer un libro, ir a un museo o ver una película, en tanto permitiría acercarse a la experiencia desde lo afectivo. He ahí su particularidad.

Por otro lado, la conexión con los hechos de terror, genera en los jóvenes la posibilidad de articular un juicio moral sobre los hechos acontecidos, posibilitando que la violencia «venga de donde venga» sea enjuiciada, o más repudiada moral, cuestión que despolitiza la acción de sus ejecutores. Y es que en esta reflexión, el derecho y respeto a la vida aparecen como un valor universal y transversal en la humanidad, imponiéndose como un valor intrínseco al ser humano.

En la misma dirección, el «nunca más» funciona como un punto de acuerdo que resulta tranquilizador para los visitantes, en tanto permite posicionar la injusticia y el terror en el pasado, resguardándolos ante el temor que dicha historia se vuelva a repetir. Un cierre, que da paso a la esperanza, en reemplazo de las emociones más angustiantes sentidas de la relación con el espacio y de las reflexiones antes vistas. Sobrevaloración de la memoria en oposición al olvido, en tanto es el recuerdo lo que puede quizás evitar que estos hechos vuelvan a ocurrir. 
Y eso me pasó, como que me dio una cuestión como no había entrado me dio una cuestión, me dije puta por eso estudiamos o por eso cada uno se dedica a hacer cierto tipo de cosas y es como lo que entregan estos lugares, cachai como dar cuenta de cosas que sí realmente pasaron y como dice el mensaje del parque, para que nunca más (Villa Grimaldi, hombre, grupo 18 a 30).

\section{POSICIONAMIENTO GENERACIONAL: «NOSOTROS, QUIENES NO LO VIVIMOS, SOMOS LA GENERACIÓN SIN MIEDO»}

Para las generaciones jóvenes las diferencias en las formas de recordar y de experimentar las emociones que surgen respecto al pasado reciente, se encuentran mediadas por el hecho de haber vivido o no determinado período histórico, por la experiencia concreta de dicho periodo - durante la Unidad Popular y la dictadura militar- y por la ideología familiar de pertenencia y las experiencias que le han sido narradas. En ese sentido, consideran que gran parte de las nociones del pasado reciente están relacionadas a dichas dimensiones contextuales. Además, la distancia sobre las experiencias represivas; es decir, qué tan lejos o cerca se estuvo de la experiencia de ser víctima de la represión política, delimita ciertas experiencias como más «verdaderas» en relación a otras menos verdaderas o, lisa y llanamente, no verdaderas.

Conforme a estas diferenciales, es que en los relatos que se despliegan en cada lugar de memoria, el ámbito generacional no está definido a partir de una edad o fecha de nacimiento, sino a partir del carácter directo o indirecto de su experiencia.

Las memorias que se construyen en el proceso de interacción con los espacios toman como punto de partida los conocimientos previos que se tienen respecto de aquello que quiere representar.

Esto implica un desafío mayor para las generaciones más jóvenes ya por lo general suelen tener escasa información sobre los lugares de memoria, su historia y su contexto de construcción. Sin embargo, para ellos resulta muy importante construir una versión «propia» de la historia, lo que los lleva a contrastar esa escasa información con lo que están observando y experimentado de forma directa y «verdadera» en la visita.

En ese horizonte se destaca la gran distancia con la que se posicionan respecto del pasado que se recuerda en dicho lugares. Para ellos y ellas el período de la dictadura es un tiempo remoto, que aunque resulta importante de conocer, recordar y transmitir a las nuevas generaciones, 
resulta ajeno y alejado de su propia realidad. Esto marca una diferencia importante en relación a las memorias de quienes vivieron la dictadura.

O sea yo no viví en esa época, pero y quizá, claro yo diga que me afecta mucho y todo, pero es muy distinto a quien vivió en esa época. Yo creo que lo debe vivir más fuerte, lo que no quiere decir que a nosotros nos importe menos, no po, al contrario, pero es distinto. Si ellos vivieron en esa época lo van a tomar de otra forma, o sea van a estar viendo algo que ocurrió mientras ellos estaban vivos y quizá le ocurría a sus pares, no sé (Villa Grimaldi, mujer, grupo 15 a 18 años).

Un elemento generacional fuerte tiene que ver con la identificación a través de su participación en el Movimiento Estudiantil. En Londres 38 esta reflexión se ve facilitada debido a museografía que alude directamente a la temática. Los jóvenes comparan las luchas y manifestaciones durante la dictadura, con las que viven hoy en día: «estamos en la misma lucha de exigir nuestros derechos».

Además, se comparara el pasado, con la participación en las protestas y marchas, situándose como «si fueran las cosas hoy de esa manera, yo podría haber sido torturado/a y asesinado/a». De este modo, la represión circula como una posibilidad, adscrita a la participación en movimientos sociales. Pese a ello, una de las características fuertes de la generación de jóvenes que «no lo vivieron» es la autodefinición como «la generación sin miedo». En los dos lugares, los participantes desplegaron memorias relacionadas a transmisión del miedo por parte de sus padres o las generaciones mayores, sobre todo en los temores de sus padres: "no vayas a la marcha, no te inscribas, no pongas tu nombre en una lista, no pongas nada en contra del gobierno», por lo que los jóvenes señalan que «aún tienen miedo», destacado que debido a que ellas/os no vivieron la represión política de la dictadura, no saben lo que es y por tanto, los libera del miedo: «yo no siento miedo porque no viví eso, no viví la represión». No se expresa en los discursos de los jóvenes una sensación de vulnerabilidad en espacios que en dictadura se experienciaron como particularmente peligrosos, como las manifestaciones en el espacio público. Esta ausencia de miedo posibilita que los jóvenes habiten estos espacios sin aparentes restricciones, afirmándose no tener temor alguno incluso en caso de ocurrir una detención. El miedo puede ser leido como un elemento crucial en la formación de una colectividad (Ahmed, 2004), en este caso una pertenencia generacional. Para Ahmed, el lenguaje del miedo opera como una intesificador de amenazas, dinstinguiendo a cuerpos 
bajo amenaza cuya movilidad se verá restringida de aquellos cuerpos que no están amenazados, tratándose de un miedo encarnado en ciertos cuerpos que han vivido experiencias particulares en contextos determinados.

Claro. Ya como la otra generación ya va a ser ya como un poquito más lejano pero todavía está como [...] De hecho el miedo de los papás con las mismas manifestaciones, de que tu mamá poco menos que [risa] [...] se le sale el corazón cuando vai a marchar o...

Acompañante - ¿Y tu decí que a tu mamá le pasa eso por...?

- Por esto, porque de alguna manera ella vivió ese tiempo entonces como que todavía existe el miedo hacia las autoridades que nosotros por lo menos no tenemos. Por lo menos yo me siento y no le tengo miedo a ninguno de las autoridades ni de hecho aunque me llevaran preso, tampoco tendría miedo. Porque como que no viví eso que realmente yo me imagino que esa gente si debería haber tenido miedo (Londres 38, hombre 15, Grupo 15 a 18).

\section{REFLEXIONES FINALES}

Las fricciones y disputas por la significación del pasado reciente adquieren mayor nitidez e inteligibilidad cuando su relato se materializa en torno al recuerdo de las violaciones de los derechos humanos. Y el recuerdo se hace más vívido aún, y con ello su disputa, cuando su habla emerge al calor de la interacción con los lugares de memoria. Como una máquina del tiempo desgarrada y desgarradora, los lugares de memoria invitan a recordar, y al mismo tiempo imaginar esas zonas abyectas de nuestra historia reciente. Experiencia encarnada, donde afectos y pensamientos se articulan en un relato que busca ser coherente, y traduce el impacto que genera el estar en esos lugares, así como conocer y/o reconocer la zona ominosa de los hechos que allí acontecieron.

Allí, esa suerte de bloque estático casi museográfico de la memoria parece dinamizarse. Y es que las generaciones de postdictadura en su interacción con los lugares de memoria lograr imaginar - ficcionar- la memoria a través de un trabajo de bricolaje, re-significando, afectándose y sobre todo proyectando, su accionar futuro. Trabajo en tensión, o si se quiere en oposición, a la autoridad asignada al recuerdo. Por esta razón, la representación homogénea de los hechos, la adecuación de la verdad sobre los hechos, se desestabiliza, tanto desde el costado conflic- 
tivo del recuerdo como desde el costado del olvido. Fundición de lo sensible, de lo visible e invisible, en cuya fragua se dejan entrever las huellas, las marcas de las diferentes posiciones generacionales.

La memoria como campo social remite a un espacio simbólico en disputa cuyos agentes participes ponen en juego su capitales simbólicos en una lucha agonística inagotable. En la misma dirección cuando De Certeau (2000) señala que solo hay una pérdida del espacio, allí donde los relatos desaparecen, o bien se degradan en objetos museográficos, lo que esta relavando es la potencia transformadora que adquiere el relato como práctica del espacio en oposición a la petrificación del discurso, el lugar y orden. En este sentido, De Certeau abre un horizonte interpretativo a partir del cual es posible leer el espacio en la significación historiográfica de la memoria como algo que excede la relación causa-efecto atribuida a la supremacía de la dimensión temporal. En efecto, si todo relato es una práctica del espacio y el espacio es un lugar practicado, entonces se entiende que todo relato efectúa un trabajo que incesantemente transforma los lugares en espacio, re-organizando los repertorios de relaciones cambiantes que los mantienen. Y esta la operación que se produce en la interacción con los lugares de memoria, en tanto sus elementos múltiples, heterogéneos y a veces hasta inconexos que los habitan son capaces de afectar a quienes los visitan, movilizando fuertes emociones, empujando a éstos no solo al recuerdo, sino también a imaginar, en definitiva, a ficcionar el pasado reciente.

En ese horizonte, la «experiencia» fundamentada en el yo estuve ahí, esgrimida por las generaciones de dictadura, funge como perspectiva privilegiada en torno a la memoria, constituyéndose en una vía regia de acceso a la supuesta memoria verdadera. En esa dirección, el relato aggiornado en la experiencia, traza una suerte de relación directa y unidireccional entre experiencia, conocimiento y posesión de la verdad, naturalizando la diferencia, y subalternizando las narrativas emergentes de las generaciones de postdictadura.

En este sentido, resulta fecunda la mirada crítica postestructuralista de Joan Scott (1991), quien problematiza el uso de la experiencia como evidencia; es decir, los modos en los cuales las narraciones de los sujetos de su propia vivencia pasan a constituir una forma de evidencia auténtica e irrefutable. Este tipo de apelación ha sido recurrente en nuestra experiencia investigativa, en la cual quienes se posicionan generacionalmente desde la experiencia vivida se constituyen como voces autorizadas para hablar desde la verdad, al mismo tiempo que se desau- 
toriza a quienes no vivieron los períodos históricos que se recuerdan. En consecuencia, cuestionar la experiencia como evidencia y autoridad es por lo tanto central para el análisis de los discursos desde una perspectiva crítica. Una perspectiva crítica que busca tensionar versiones hegemónicas del pasado, reconociendo el carácter constructor de sujetos y realidades de las prácticas colectivas de memoria, y reconociendo sobre todo que es en este carácter que radica el potencial transformador y por lo tanto político de las practicas de memoria colectiva.

$\mathrm{Al}$ respecto, Scott argumenta que esta apelación a la experiencia como verdad no da cabida a historias diferentes. Simultáneamente la identidad de quienes documentan sus experiencias es abordada como evidente en sí misma, y las diferencias entre sujetos son naturalizadas. Cuando la experiencia pasa a ser concebida como el origen del conocimiento, ya no es posible dar cabida a preguntas acerca de la naturaleza construida de la experiencia y de cómo los sujetos son constituidos de diferentes maneras por estas experiencias y de qué manera se estructura la visión de cada uno/a. Razón por o cual, una mirada postestructuralista busca preguntarse más bien por los modos en los cuales se establece la diferencia, como esta opera, y de qué manera constituye sujetos que ven y actúan en el mundo. Cuando la experiencia opera como evidencia, y el significado es considerado transparente, ésta opera reproduciendo en vez de cuestionando sistemas ideológicos dados, asumiéndose que los hechos hablan por sí mismos (Scott, 1991).

Es en esta línea que nos interesa problematizar la memoria oficial hegemónica de quienes se sitúan desde la autoridad del haber vivido la dictadura, ya que la oficialización y cristalización de ésta opera invisibilizando y marginando otras memorias posibles, en este caso memorias de jóvenes nacidos en postdictadura. Se trata de facilitar condiciones que potencialmente pueden posibilitar nuevos campos de sentido que le otorgarán a la memoria el poder de construir versiones contrahegemónicas mediante la articulanción de saberes, afectos e identidades sobre el pasado, que se encuentran siempre abiertas a resignificación (Piper, Fernández e Iñíguez, 2013).

Carles Feixa (1999), siguiendo a Gramsci, nos recuerda que la hegemonía guarda gran relación con la cuestión juvenil en tanto que por una parte, la educación de las nuevas generaciones es fundamental en la reproducción de una obra hegemónica, y por otra parte, estos mismos jóvenes jugarán un papel clave como paradigmas de las crisis de autoridad, crisis que en la práctica pondrán de manifiesto la crisis de la hegemonía (Feixa, 1999). Al respecto, sirva como botón de 
muestra de la disputa hegemonía/contrahegemonía y del carácter relacional que posee la categoría «joven», el siguiente fragmento de una conversación tomada de un grupo triangular de jóvenes en la que se refieren a las operaciones que colocan a la experiencia como fundamento y las respuestas orientadas a su desmontaje.

O sea si uno, aparte que hay gente que es súper básica pos, entonces... eh... si tú hablai con un adulto, más adulto y le decís, empezai a hablar sobre temas de derechos humanos o del golpe, dicen pero si tú no viviste esa época, ése es el argumento, yo le dije, yo siempre ocupo el contraargumento mío es, bueno ¿usted vivía en la época de OHiggins? Entonces ahí dicen ah no, no pero el padre de la patria, más o menos, es la historia pos viejo, cachai, es parte de esto pos, sino...

SANTIAGO (CHILE), DICIEMBRE 2014

RECIBIDO: DICIEMBRE 2014 ACEPTADO: MARZO 2015 


\section{REFERENCIAS BIBLIOGRÁFICAS}

Ahmed, SARA (2004): The Cultural Politics of Emotion. Edinburgh: Edinburgh University Press.

BAUMAN, ZYGMUNT (2007): «Between Us, the Generations». En J. LARROSA (Ed.): On Generations. On coexistence between generations. Barcelona: Fundació Viure I Conviure.

BOURDIEU, PIERRE (1990): Sociología y cultura. México: Editorial Grijalbo.

- (2001): Poder, derecho y clases sociales. Bilbao: Editorial Desclée de Brouwer.

— - y LOÍc WACQUANT (2005): Una invitación a la sociología reflexiva. Buenos Aires: Siglo Veintiuno Editores.

CAlveiro, Pilar (2006): «Los usos políticos de la memoria». En: Sujetos sociales y nuevas formas de protesta.

CONDE, FERNANDO (2008): «Los grupos triangulares como espacios transicionales para la producción discursiva: un estudio sobre la vivienda en Huelva». En GORDO y SERRANO (Coord.) Estrategias y prácticas cualitativas de investigación social. Madrid: Pearson Prentice Hall.

DE CERTEAU, Michel (2000): La invención de lo cotidiano I. Artes de hacer. México: Universidad Iberoamericana, Instituto Tecnológico y de Estudios Superiores de Occidente.

FeIXA, CARLeS (1999): De jóvenes, bandas y tribus. Barcelona: Editorial Ariel.

FONDECYT (2011): «Construcción de relatos generacionales sobre nuestro pasado reciente (1970-1990) en el escenario de cuatro lugares de memoria de Santiago». (FONDECYT Regular No 1110162).

GARCÍA, ANDRÉS (2001): «Introducción. La razón del derecho: entre habitus y campo». En PIERRE BOURDIEU: Poder, derecho y clases sociales. Bilbao: Editorial Desclée de Brouwer.

GUICHARD, EDUARDO y GUILLERMO HENRÍQUEZ (2011): «Memoria histórica en Chile: una perspectiva intergeneracional desde Concepción». Reis: Revista Española de Investigaciones Sociológicas $\mathrm{N}^{\circ} 135$.

GROPPO, B. (2002): «Las políticas de la memoria». Sociohistórica $\mathrm{N}^{\circ} 11-12$. Disponible en: www.memoria.fahce.unlp.edu.ar.

HALbWAChS, MAURICE (2004): La memoria colectiva. Zaragoza: Prensas Universitarias de Zaragoza.

HEVIA, EVELYN e ISABEL PIPER (2012): Espacio y recuerdo: archipiélago de memorias en Santiago de Chile. Santiago: Ocho Libros.

JEFFERSON, G. (1985): «An exercise in the transcription and analysis of laughter». En T. VAN DIJK (Ed.): Handbook of Discourse Analysis, Vol. 3: Discourse and Dialogue. Londres: Academic.

JeLIN, ElizABETH (2001): «¿De qué hablamos cuando hablamos de memorias? ». En E. JeLIN: Los trabajos de la memoria. Madrid: Siglo Veintiuno Editores. 
- y VictORIA LANGLAND (2003): «Las marcas territoriales como nexo entre pasado y presente». En E. JELIN y V. LANGLAND (Comp.): Мопиmentos, memoriales y marcas territoriales. Madrid: Siglo XXI.

LÓPEZ, LORETO (2010): «Lugares de memoria de las violaciones a los derechos humanos: más allá de sus límites». En: Recordar para pensar. Memoria para la democracia. La elaboración del pasado reciente en el Cono sur de América Latina. Santiago: Ediciones Böll Cono Sur.

MANNHEIM, KARL (1993): «El problema de las generaciones». Reis: Revista Española de Investigaciones Sociológicas $\mathrm{N}^{\circ} 96$.

NORA, PIERRE (2009): Les Lieux de la memoire. Santiago: LOM Ediciones.

PIPER, ISABEL (2002): «Sobre una práctica que, en el sur, se llama a sí misma psicología social crítica». En ISABEL PIPER (Comp.): Políticas, sujetos y resistencias. Debates y críticas en psicología social. Santiago: Arcis. (2010): «Proyecto usos del espacio, identidades sociales y políticas del recuerdo. Análisis psicosocial de lugares de memoria de los conflictos violentos de nuestro pasado reciente Santiago-Chile». En: Procesos de memoria, ciudadanía y recuperación d lugares de conciencia. Encuentro y taller. Santiago: Corporación Villa Grimaldi.

—_, ROBERTO FERNÁNDEZ y LUPICINIO IÑIGUEZ (2013): «Psicología social de la memoria: espacios y políticas del recuerdo». Psykhe, Vol. 22, №2.

REgUiLlo, Rossana (2000): Emergencia de culturas juveniles. Estrategias del desencanto. Buenos Aires: Grupo Editorial Norma.

ReYes, María José, JuAN MuÑoz y FéliX VÁzQUez (2013): «Políticas de memoria en los discursos cotidianos: la despolitización en del pasado reciente en el Chile actual». Psykhe, Vol. 22, №2.

RICHARD, NELlY (2010): Crítica de la memoria. Santiago. Ediciones Universidad Diego Portales.

SCOTT, JOAN (1991): «The evidence of experience». Critical Inquiry $\mathrm{N}^{\circ} 17$.

TOCORNAL, XIMENA y MARÍA VERGARA (1998): «La memoria del régimen militar. Un análisis psicosocial desde la perspectiva socioconstruccionista». Documento de Trabajo $\mathrm{N}^{\circ} 35$. Santiago: Centro de Investigaciones Sociales, Universidad Arcis.

VÁZQUEZ, FÉLIX (2001): La memoria como acción social. Relaciones, significados e imaginario. Barcelona: Paidós.

\section{Páginas Web Consultadas:}

www.londres38.cl.

www.museodelamemoria.cl.

www.villagrimaldi.cl.

www.memoriaviva.cl. 